\title{
Spectrometric Studies on Sodium Nitroprusside and its Interaction with HSA upon Photoirradiation
}

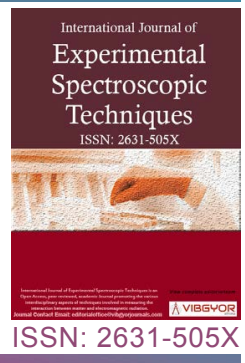

\section{Lifang Liu' ${ }^{1}$ Zhiou Ma', Leilei Xie' ${ }^{1}$, Xiaolu Wang', Wenming Wang' and Hongfei Wang ${ }^{1,2}$}

${ }^{1}$ Key Laboratory of Chemical Biology and Molecular Engineering of Education Ministry, Institute of Molecular Science, Shanxi University, Taiyuan, China

${ }^{2}$ Key Laboratory of Energy Conversion and Storage Materials of Shanxi Provence, Institute of Molecular Science, Shanxi University, Taiyuan, China

\begin{abstract}
Sodium nitroprusside (SNP, $\mathrm{Na}_{2}\left[\mathrm{Fe}(\mathrm{CN})_{5} \mathrm{NO}\right] \cdot 2 \mathrm{H}_{2} \mathrm{O}$ ) has been widely applied clinically as a vasodilator and a drug by releasing NO. In this work, photo-induced NO release from SNP was investigated using electron paramagnetic resonance spectroscopy and the spin trapping shows a characteristic triplet signal of NO free radicals. The dynamic process and mechanism of NO release from SNP upon photoirradiation were further analyzed using time-resolution infrared spectroscopy technology. SNP can bind with human serum albumin (HSA), which was proven by the observation of the blue-shift of the NO vibrational peak. Spectrometric measurement provides method to analyze the photodynamic process of SNP for better understanding of its pharmacological activity and establishes a basis for attempted applications in clinical therapy.
\end{abstract}

\section{Keywords}

Sodium nitroprusside, Nitric oxide donor, Protein, Photodynamic, Spectral analysis

\section{Introduction}

Sodium nitroprusside (SNP) is a well-known arterial and venous vasodilator, which has been used in clinical practice to lower blood pressure and other clinical applications for 40 years [1-4]. This prodrug reacts with physiologic sulfhydryl groups to release nitric oxide (NO), causing rapid vasodilation and acutely lowering blood pressure [1]. NO is an important signal molecule and plays a significant role in many physiological and biochemical processes, including signal transmission in the nervous sys- tem, immune responses, and cell apoptosis [5-7]. SNP is easily decomposed to produce NO; however, it releases NO spontaneously. With the development of photodynamic therapy, photo-controlled NO release has attracted much attention $[8,9]$.

SNP is a water-soluble sodium salt comprised of $\mathrm{Fe}^{2+}$ ions complexed with $\mathrm{NO}$ and five cyanide anions, it is unstable and possibly produces $\mathrm{CN}^{-}$during release of NO though photodegradation or reacts with oxyhemoglobin to form methemoglobin and release cyanide anions in vivo $[1,10]$. Despite the

*Corresponding author: Hongfei Wang, Key Laboratory of Chemical Biology and Molecular Engineering of Education Ministry; Key Laboratory of Energy Conversion and Storage Materials of Shanxi Provence, Institute of Molecular Science, Shanxi University, Taiyuan 030006, China

Accepted: October 23, 2018; Published: October 25, 2018

Copyright: (c) 2018 Liu L, et al. This is an open-access article distributed under the terms of the Creative Commons Attribution License, which permits unrestricted use, distribution, and reproduction in any medium, provided the original author and source are credited. 
concerns about the cyanide toxicity [11], SNP has continued to be used in many clinical therapies for its potent and fast-acting vasodilatory properties. Therefore, further research is necessary to investigate the pharmacological properties of SNP to improve its therapeutic effects and reverse its side effects.

In this work, the NO release from SNP solution upon photoirradiation at different wavelengths was measured quantificationally, and the basic method of adjusting NO release with irradiation wavelength was studied. The dynamic process of SNP upon photoirradiation was monitored with time-resolution Fourier-transform infrared (FTIR) spectroscopy, and the mechanism was analyzed using two-dimensional correlation spectroscopy (2D COS) technology. Furthermore, the kinetic interactions between SNP and the human serum albumin (HSA) upon photoirradiation were studied. It provides a new basis for understanding its physicochemical properties, photoinduced biological effects, and potential applications in clinical therapy.

\section{Experimental}

\section{Materials and methods}

SNP was purchased from Sigma (St. Louis, MO, USA). HSA was purchased from Salarbio (Beijing, China). The spin trapper $\mathrm{N}$-methyl-D-glucamine dithiocarbamate (MGD) was purchased from Dojindo (Kumamoto, Japan). Other chemical reagents and solvents were purchased from local sources.

Electron paramagnetic resonance (EPR) spectra were obtained using a Bruker ESP-500E spectrometer at $9.8 \mathrm{GHz}, \mathrm{X}$ band, with $100 \mathrm{~Hz}$ field modulation. SNP ( $5 \mathrm{mM}$ ) mixed with $5 \mathrm{mM} \mathrm{Fe}(\mathrm{MGD})_{2}$ were quantitatively injected into quartz capillaries separately. The samples were illuminated in the cavity of the EPR spectrometer with an Nd:YAG laser at $532 \mathrm{~nm}$ ( 5 to $6 \mathrm{~ns}$ of pulse width, $10 \mathrm{~Hz}$ of repetition, $10 \mathrm{~mJ} /$ pulse). Nanosecond laser pulses for excitation at $355 \mathrm{~nm}$ were generated by an $\mathrm{Nd}^{3+}:$ YAG laser, the excitation energy of each pulse was $3 \mathrm{~mJ}$. The spectra were recorded after appropriate intervals $(30,60,120,180,300$ and $600 \mathrm{~s})$. All measurements were performed at room temperature.

Quantitative measurements of released NO upon photo irradiation were conducted by TBR4100 four-channel free radical analyzer (World Precision Instruments, USA) equipped with a wide range NOselective electrode. The ISO-NOP NO meter $(2 \mathrm{~mm})$ was vertically and directly immersed inside the quartz cuvette containing $10 \mu \mathrm{M}$ complex solution in $10 \mathrm{mM}$ phosphate buffer at $\mathrm{pH}$ 7.4. The NO release profile was constructed by plotting the current versus time. Samples in the quartz cuvette were irradiated by a Xe lamp at the central wavelengths of $254 \mathrm{~nm}, 420$ $\mathrm{nm}, 470 \mathrm{~nm}$ and $550 \mathrm{~nm}$ with a band-pass filters. The irradiation power was measured with an optical power meter and was kept constant at $0.2 \mathrm{~W} / \mathrm{cm}^{2}$.

IR spectra were recorded on an IS50R FTIR spectrometer (Thermo Electron) ranging from 2200 to $1800 \mathrm{~cm}^{-1}$ at $1-\mathrm{cm}^{-1}$ resolution. The photoreaction kinetics was monitored by the evolution of the IR spectrum as a function of the irradiation time. The SNP was dissolved in water or water/dimethyl sulfoxide (1:5) mixture solution at appropriate concentrations, the sample solutions filled an IR cell composed of two $\mathrm{CaF}_{2}$ windows of $25 \mathrm{~mm}$ diameter and $2 \mathrm{~mm}$ thickness that were separated by an "O"-shaped Teflon ${ }^{\mathrm{m}}$ spacer of $50 \mu \mathrm{m}$ thickness. The samples were irradiated using fiber optics connected to a Xe lamp with 420-nm band-pass filters. The serial data collections were recorded in $30 \mathrm{~min}$, and the scan interval is $40 \mathrm{~s}$.

The interactions of SNP with HSA were studied by fluorescence spectroscopy. The fluorescence intensities were measured at an excitation wavelength of $280 \mathrm{~nm}$, and the fluorescence emission was recorded from 300 to $500 \mathrm{~nm}$. A series of complex solutions ( $3 \mathrm{mM}$ ) were added to HSA solutions $(5 \mu \mathrm{M})$ to attain a final volume of $2 \mathrm{~mL}$. The binding constant $\left(K_{b}\right)$ was obtained from the Scatchard equation from a Scatchard plot of $r / C_{f}$ versus $r$, where $r$ is the $C_{b} /[H S A]$ value, $C_{f}$ and $C_{b}$ are the concentration of free and binding complex, respectively [12]. Fluorescent spectra were recorded on a Hitachi-4500 fluorescence spectrometer. After HSA $\left(1.0 \times 10^{-3} \mathrm{M}\right)$ and SNP $\left(1.0 \times 10^{-3} \mathrm{M}\right)$ were mixed, IR cells were filled with the solution, and then the FTIR spectra were measured after appropriate intervals.

\section{Results and Discussion}

\section{Photo-controlled NO release}

The photoinduced NO release from SNP was analyzed using EPR spectra and spin trapping using $\mathrm{Fe}(\mathrm{MGD})_{2}$, which is the reliable methods for detecting NO in real time at its generation site $[13,14]$. Figure 1 shows the characteristic triplet signal with a hyperfine splitting constant (hfsc) value of $a_{N}=12.78 \mathrm{G}$ and a $g$ factor of $g=2.039$, which is 

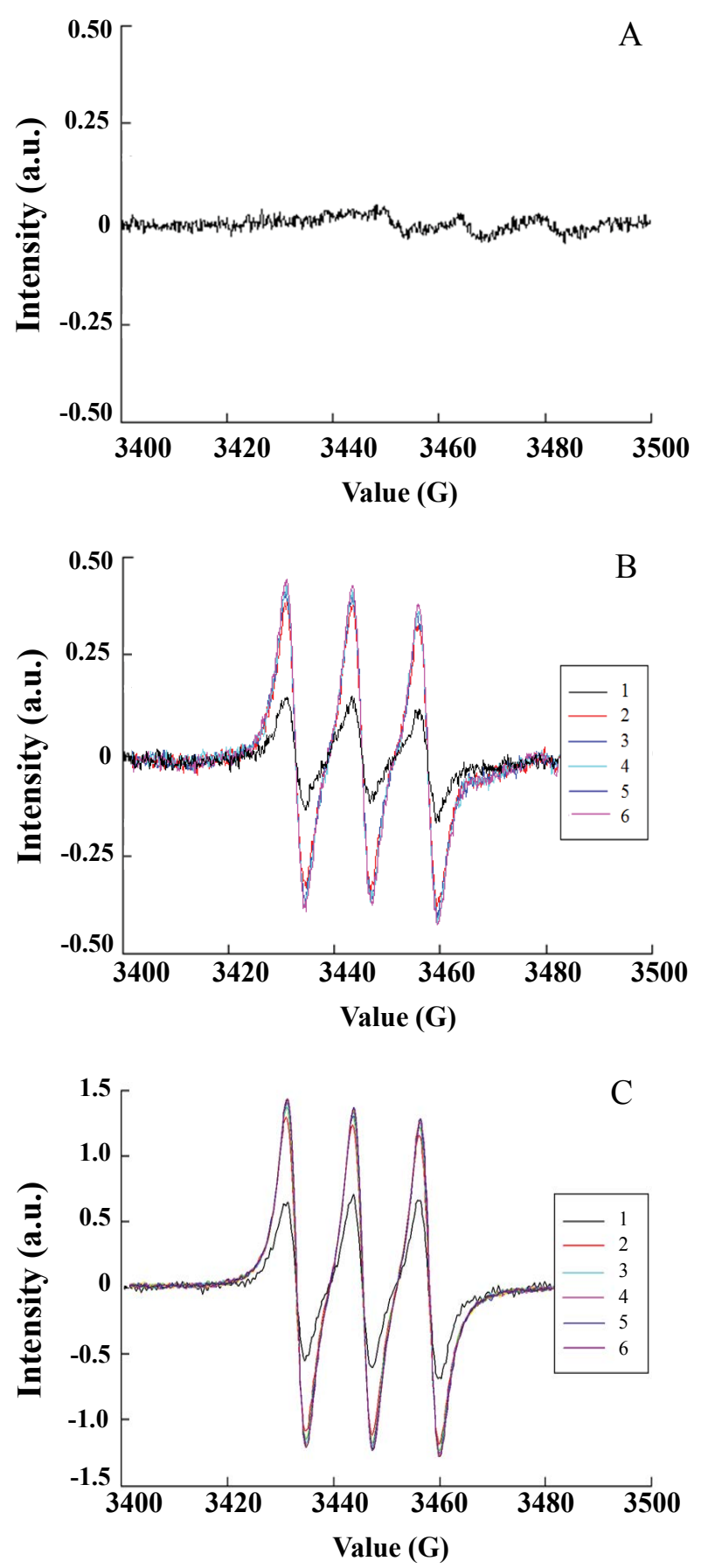

Figure 1: Triplet EPR signals caused by NO trapped by Fe-MGD in SNP solution. A) Control without photoirradiation; B) Photoirradiation at $532 \mathrm{~nm} .1$, $30 \mathrm{~s} ; 2,60 \mathrm{~s} ; 3,120 \mathrm{~s} ; 4,180 \mathrm{~s} ; 5,300 \mathrm{~s} ; 6,600 \mathrm{~s} ;$ C) Photoirradiation at $355 \mathrm{~nm} .1,30 \mathrm{~s} ; 2,60 \mathrm{~s} ; 3,120 \mathrm{~s}$; 4, 180 s; 5, 300 s; 6, 600 s.

consistent with published values for $\mathrm{NO}-\mathrm{Fe}^{2+}-\mathrm{MGD}$ adduct $[15,16]$. No obvious signal was observed in the dark, as shown in Figure 1A. Large amounts of free-radical molecules were generated from SNP with photoirradiation at $355 \mathrm{~nm}$ and $535 \mathrm{~nm}$. The intensity of produced free radicals increased quickly and reached a maximum after $60 \mathrm{~s}$ (Figure 1B and

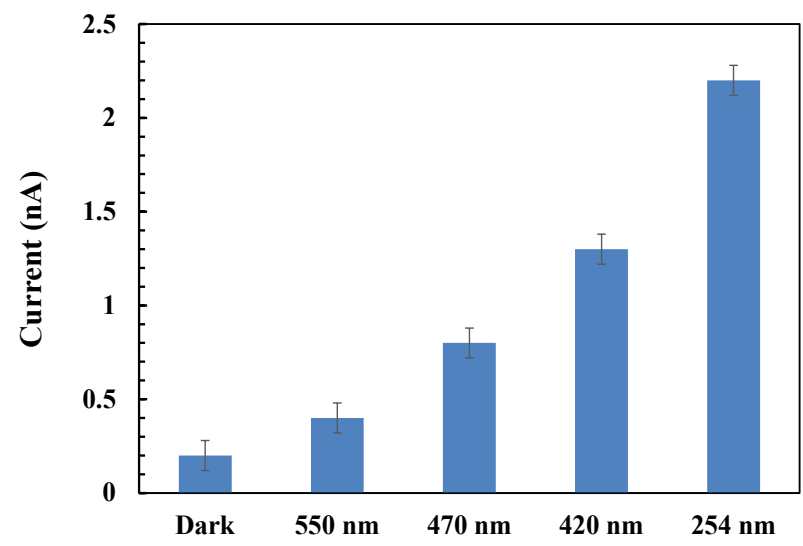

Figure 2: Effect of irradiation wavelengths on the amount of NO release from SNP.

Figure $1 C$ ), the trapped free radicals can stably exist for over 10 mins. Furthermore, the signal intensity of released NO increased obviously as the irradiated wavelength changed from $532 \mathrm{~nm}$ to $355 \mathrm{~nm}$.

Real-time NO release upon photo-irradiation was measured with the free radical analyzer using a NO-selective electrode. As shown in Figure 2, the amount of released NO from SNP increased at the photoexcitation of $550 \mathrm{~nm}, 470 \mathrm{~nm}, 420 \mathrm{~nm}$ and $254 \mathrm{~nm}$, respectively. The NO release increased as the irradiated wavelength moving from visible region to UV region, which is consistent with the change of absorption spectra for SNP. The max absorption peak for SNP is in the UV region and the absorption peak declines gradually in visible region. Therefore, the NO release could be controlled by adjusting the irradiation wavelength, it provides a basis for further applications in photochemistry and photobiology.

\section{FTIR spectral studies}

The photoinduced decomposition of SNP was further monitored by IR spectra. The change of FTIR spectrum for SNP in water and dimethyl sulfoxide mixture solution before and after photoirradiation are shown in Figure 3. Two new peaks around $2080 \mathrm{~cm}^{-1}$ and $2058 \mathrm{~cm}^{-1}$ were observed. Detailed electronic structure and possible dissociation process for SNP were analyzed, it decomposed and released NO and cyanides [17]. After the solutions of SNP were irradiated at room temperature for $20 \mathrm{~min}$, there is an obvious decrease in the vibrational peak of $\mathrm{NO}$ and $\mathrm{CN}$ groups in SNP molecules (Figure $4 \mathrm{~A}$ and $4 \mathrm{C}$ ), which is consistent with that of Figure 3. This indicated the dissociation of SNP. Two new peaks $\left(2080.5 \mathrm{~cm}^{-1}\right.$ and $2058.3 \mathrm{~cm}^{-1}$ ) increased gradually, which possibly 


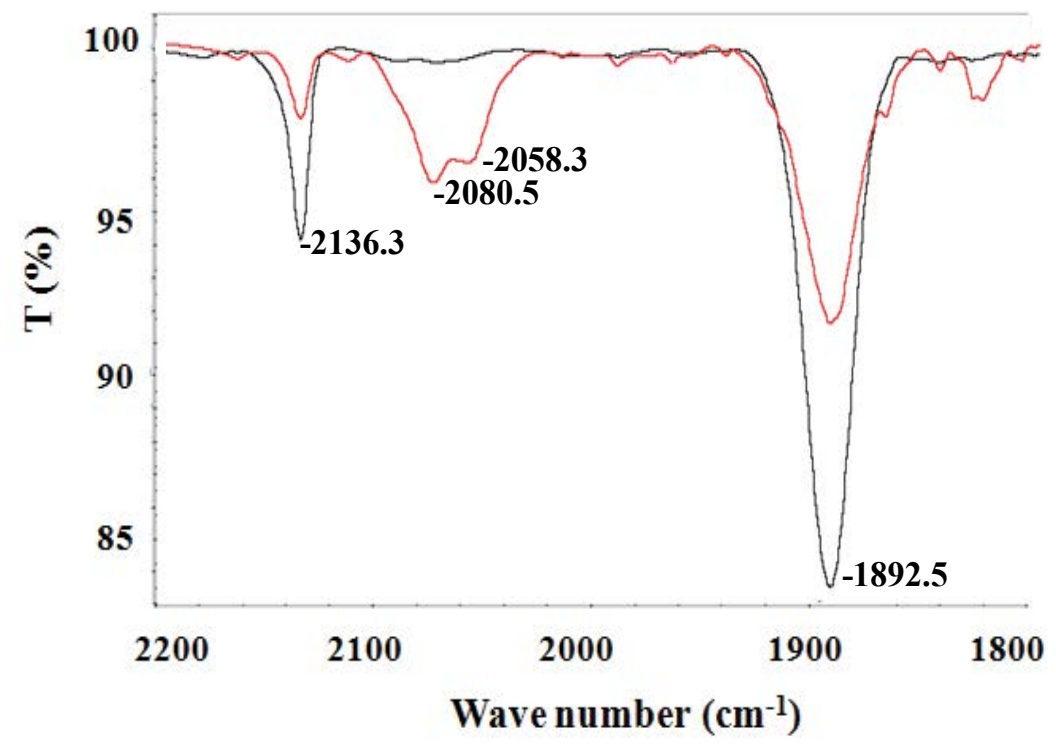

Figure 3: FTIR spectrum of SNP upon photoirradiation in water/dimethyl sulfoxide (1:5) mixture solution (red curve, after $20 \mathrm{~min}$ of photoirradiation).
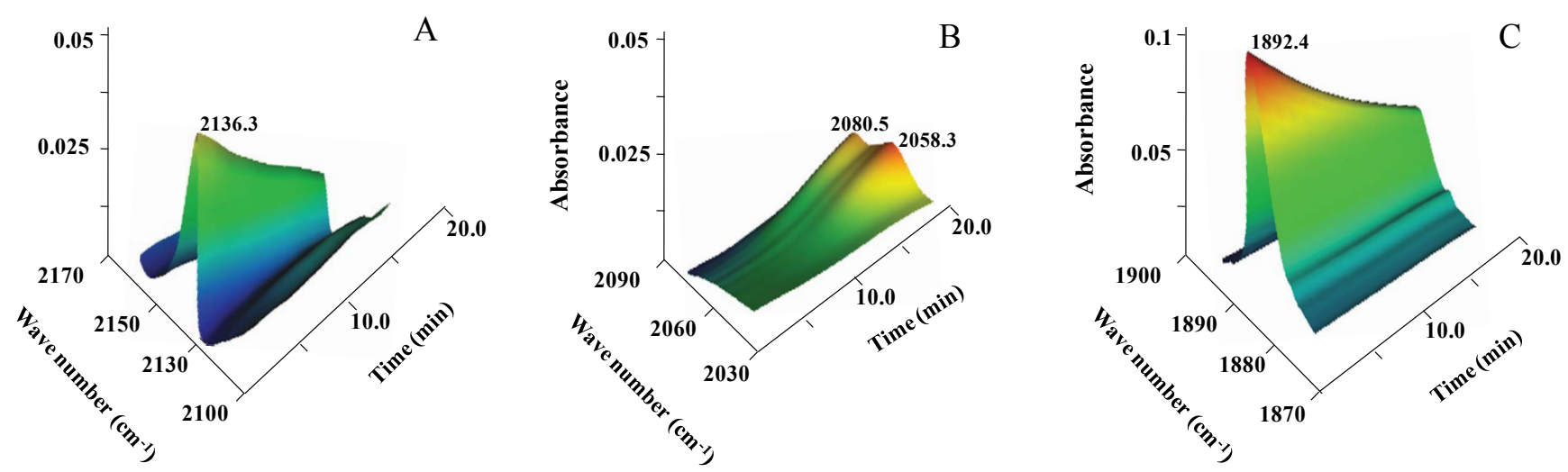

Figure 4: Photoreaction kinetics of SNP monitored via the IR spectra as a function of irradiation time in different vibrational frequence regions. (A) $2100 \sim 2170 \mathrm{~cm}-1$; (B) $2030 \sim 2090 \mathrm{~cm}-1$; (C) $1870 \sim 1900 \mathrm{~cm}-1$.

correspond to the vibration of the $\mathrm{CN}$ group in the decomposed Fe complex (Figure 4B).

\section{Protein binding properties}

The interaction of SNP with proteins is important because it is crucial for biodistribution and underlying pharmacological mechanisms $[18,19]$. Figure 5A shows the qualitative analysis of SNP bound to HSA, determined by examining the fluorescence spectra. Fluorescence quenching refers to any process that decreases the fluorescence intensity of a fluorophore due to a variety of molecular interactions $[20,21]$. The intrinsic binding constants $\left(K_{b}\right)$ of SNP were calculated using a modified Scatchard equation $[22,23]$. The calculated binding constant $\left(K_{\mathrm{b}}\right)$ with HSA was $2.3 \times 10^{3} \mathrm{M}^{-1}$, and the calculated average binding-site number was 0.96 , close to one.
To further investigate the possible binding mode that occurred to HSA upon addition of the complexes, the IR spectra of HSA mixed with SNP in water were measured. The spectral changes of the SNP mixed with HSA are shown in Figure $5 \mathrm{~B}$. The characteristic vibrational spectrum of NO in SNP exhibited an obvious blue-shift from 1935 to $1910 \mathrm{~cm}^{-1}$, and the decrease of the vibrational peak at 1935 $\mathrm{cm}^{-1}$ for NO was promoted with photoirradiation. The vibrational frequencies of NO in the protein molecule are related to their surroundings; changes in the NO vibrational frequencies suggest that SNP can bind with HSA, and that HSA was possibly modified with released NO upon photoirradiation.

\section{Conclusions}

Sodium nitroprusside (SNP) is one of the most effective vasodilators and has been widely applied 

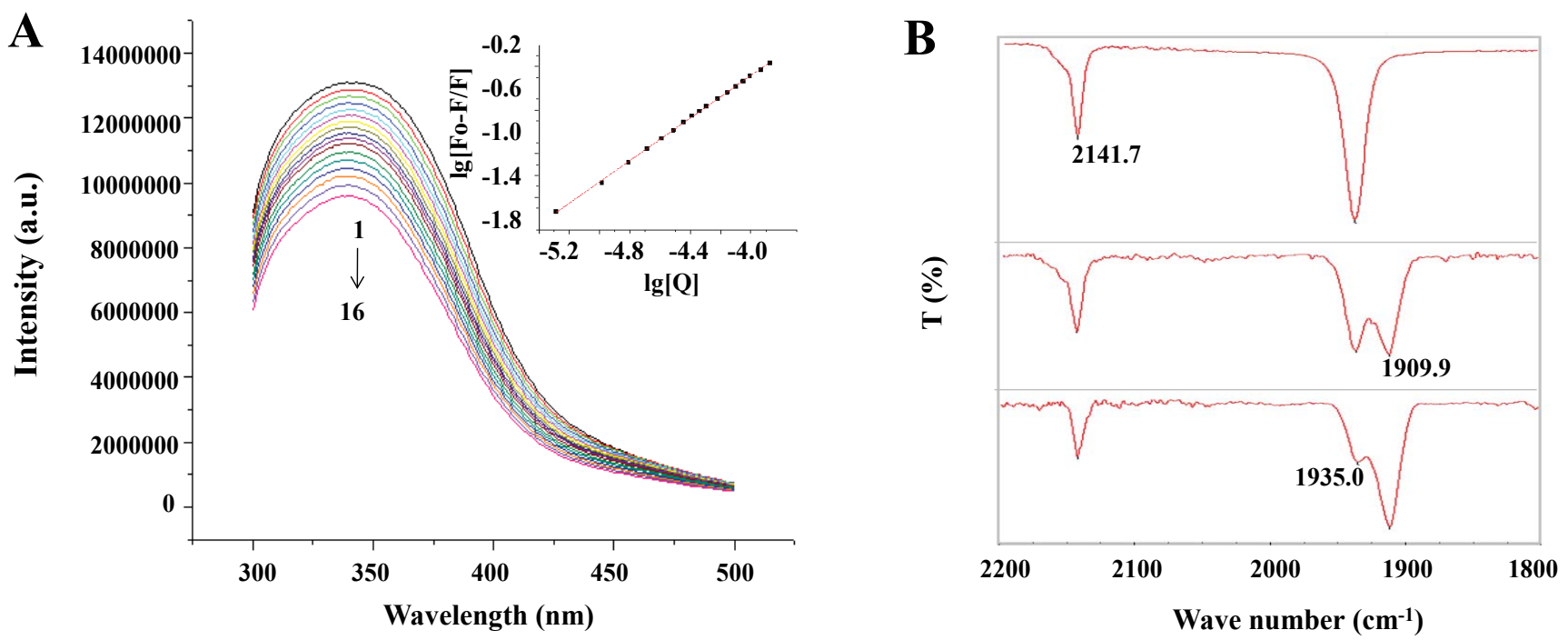

Figure 5: A) Emission spectra of HSA ( $5 \mu \mathrm{M})$ titrated with SNP complex in buffer solution; the arrows show the intensity changes upon increasing concentrations of SNP (1-16: 0-140 $\mu \mathrm{M}$, respectively); B) IR spectra of HSA mixed with SNP upon photoirradiation in water solution. 1, $1 \mathrm{mM} \mathrm{SNP;} \mathrm{2,} 1 \mathrm{mM} \mathrm{SNP}+1 \mathrm{mM} \mathrm{HSA} ; 3,1 \mathrm{mM}$ SNP $+1 \mathrm{mM}$ HAS upon photoirradiation after $20 \mathrm{~min}$.

in clinical therapy. We investigated the dynamic process of SNP upon photoirradiation, which provided the foundation for attempted applications in clinical therapy. The photo-controlled NO release from SNP was proved using EPR spectroscopy, and a simple method to control NO release quantitatively with photoirradiation at different wavelengths in aqueous solutions was developed. Combined with the time-resolved IR spectral measurements, the mechanisms for dissociation of NO were clarified. Moreover, SNP can bind with HSA and is possibly modified by released NO upon photoirradiation, the spectroscopic studies provided better understanding for the pharmacological activities and potential applications of SNP.

\section{Competing Interests}

All of the authors declare that they have no competing interests.

\section{Acknowledgments}

This work was partially supported by the National Natural Science Foundation of China (Grant No. 21671125, 21601112, and 21543003) and by the Research Projects of Shanxi Province (Grant Nos. 2015081049 and 2015-021). The beam time provided by the Beijing Synchrotron Radiation Facility (BSRF) and the Shanghai Synchrotron Radiation Facility (SSRF) is also acknowledged.

\section{References}

1. Hottinger DG, Beebe DS, Kozhimannil T, Prielipp RC,
Belani KG (2014) Sodium nitroprusside in 2014: A clinical concepts review. J Anaesthesiol Clin Pharmacol 30: 462-471.

2. Metsios GS, Stavropoulos-Kalinoglou A, Veldhuijzen van Zanten JJ, Nightingale $P$, Sandoo $A$, et al. (2014) Individualised exercise improves endothelial function in patients with rheumatoid arthritis. Ann Rheum Dis 73: 748-751.

3. Sharma N, Bhattarai JP, Hwang PH, Han SK (2013) Nitric oxide suppresses L-type calcium currents in basilar artery smooth muscle cells in rabbits. Neurol Res 35: 424-428.

4. Wang H, Wang AX, Aylor K, Barrett EJ (2013) Nitric oxide directly promotes vascular endothelial insulin transport. Diabetes 62: 4030-4042.

5. Fukumura D, Kashiwagi S, Jain RK (2006) The role of nitric oxide in tumour progression. Nat Rev Cancer 6: 521-534.

6. Lundberg JO, Gladwin MT, Ahluwalia A, Benjamin N, Bryan NS, et al. (2009) Nitrate and nitrite in biology, nutrition and therapeutics. Nat Chem Biol 5: 865869.

7. Tennyson AG, Lippard SJ (2011) Generation, translocation, and action of nitric oxide in living systems. Chem Biol 18: 1211-1220.

8. Reeves KJ, Reed MW, Brown NJ (2010) The role of nitric oxide in the treatment of tumours with aminolaevulinic acid-induced photodynamic therapy. J Photochem Photobiol B 101: 224-232. 
9. Burks PT, Garcia JV, Gonzalezlrias R, Tillman JT, Niu $M$, et al. (2013) Nitric oxide releasing materials triggered by near-infrared excitation through tissue filters. J Am Chem Soc 135: 18145-18152.

10.Arnold WP, Longnecker DE, Epstein RM (1984) Photodegradation of sodium nitroprusside: Biologic activity and cyanide release. Anesthesiology 61: 254260.

11. Nagasawa HT, Goon DJ, Crankshaw DL, Vince R, Patterson SE (2007) Novel, orally effective cyanide antidotes. J Med Chem 50: 6462-6464.

12.Mc Ghee JD, von Hippel PH (1974) Theoretical aspects of DNA-protein interactions: Co-operative and non-co-operative binding of large ligands to one-dimensional homogeneous lattice. J Mol Biol 86: 469489.

13.Vanin AF, Poltorakov AP, Mikoyan VD, Kubrina LN, van Faassen E (2006) Why iron-dithiocarbamates ensure detection of nitric oxide in cells and tissues. Nitric Oxide 15: 295-311.

14.Porasuphatana S, Weaver J, Budzichowski TA, Tsai P, Rosen GM (2001) Differential effect of buffer on the spin trapping of nitric oxide by iron chelates. Anal Biochem 298: 50-56.

15.Gopalakrishnan B, Nash KM, Velayutham M, Villamena FA (2012) Detection of nitric oxide and superoxide radical anion by electron paramagnetic resonance spectroscopy from cells using spin traps. J Vis Exp 66: e2810.

16.Pou S, Tsai P, Porasuphatana S, Halpern HJ, Chandramouli GV, et al. (1999) Spin trapping of nitric oxide by ferro-chelates: kinetic and in vivo pharmaco- kinetic studies. Biochim Biophys Acta 1427: 216-226.

17. Olabe JA (2008) The coordination chemistry of nitrosyl in cyanoferrates. An exhibit of bioinorganic relevant reactions. Dalton Trans 28: 3633-3648.

18.Fanali G, di Masi A, Trezza V, Marino M, Fasano M, et al. (2012) Human serum albumin: From bench to bedside. Mol Asp Med 33: 209-290.

19.Luo M, Boudier A, Pallotta A, Maincent P, Vincourt $\mathrm{JB}$, et al. (2016) Albumin as a carrier for NO delivery: Preparation, physicochemical characterization, and interaction with gold nanoparticles. Drug Dev Ind Pharm 42: 1928-1937.

20.Tayeh N, Rungassamy T, Albani JR (2009) Fluorescence spectral resolution of tryptophan residues in bovine and human serum albumins. J Pharm Biomed Anal 50: 107-116.

21.Dömötör O, Hartinger CG, Bytzek AK, Kiss T, Keppler BK, et al. (2013) Characterization of the binding sites of the anticancer ruthenium(III) complexes KP1019 and KP1339 on human serum albumin via competition studies. J Biol Inorg Chem 18: 9-17.

22.Xu L, Hu YX, Li J, Liu YF, Zhang L, et al. (2017) Probing the binding reaction of cytarabine to human serum albumin using multispectroscopic techniques with the aid of molecular docking. J Photochem Photobiol B 173: 187-195.

23.Thota $S$, Vallala $S$, Yerra R, Rodrigues DA, Raghavendra NM, et al. (2016) Synthesis, characterization, DNA binding, DNA cleavage, protein binding and cytotoxic activities of Ru(II) complexes. Int J Biol Macromol 82: 663-670. 